\title{
Los precios de la carne vacuna en Buenos Aires colonial. Una interpelación historiográfica e histórica
}

\section{The prices of beef on colonial Buenos Aires. A historiographical and historical interpellation}

\author{
Andrea Dupuy \\ Universidad Nacional de Mar del Plata - Grupo de Investigación: \\ Problemas y Debates del siglo XIX - CEHIS - Dpto. de Historia - Facultad de \\ Humanidades - Universidad de Mar de Plata. \\ aldupuy@mdp.edu.ar \\ Fecha de recepción 3 de febrero de 2014 \\ Fecha de aceptación 26 de mayo de 2014
}

\section{Resumen}

En el ámbito de los estudios de mercado, los precios constituyen los principales indicadores del comportamiento de la economía, aun los de Antiguo Régimen. El objetivo del presente trabajo es abordar el análisis de los precios de la carne vacuna de la ciudad de Buenos Aires colonial partiendo de la idea de que este mercado, al igual que los de las distintas ciudades hispanoamericanas, presentó a lo largo de la etapa colonial una regularidad predominante. $Y$ aun cuando estuvo atravesado por situaciones críticas de escasez, estos factores no lograron modificar sustancialmente, desde una mirada de largo plazo, las características del mismo.

Palabras clave: Mercado local, abasto, carne vacuna, regularidad.

Clasificación JEL: N9, N96 


\begin{abstract}
In the field of market research, prices are the main performance indicators of the economy, even the one of the old regime. The objective of this work is to approach the research of the prices of beef on Buenos Aires colonial city based on the idea that this market, as those of different Spanish American cities, showed throughout the colonial era predominant regularity. Even when it was crossed by critical shortage situations, these factors were not able to substantially change, from a long term perspective, their characteristics.
\end{abstract}

Keywords: Local market, supply, beef, regularity.

JEL Codes: N9 , N96 


\section{Introducción}

Volver nuestra mirada sobre la problemática de los precios de la carne vacuna para el consumo en la ciudad de Buenos Aires colonial responde a un intento de organizar y sistematizar los estudios históricos e historiográficos sobre el tema y averiguar de qué modo este alimento, parte de la dieta cotidiana de los habitantes de esta ciudad, incide en el contexto de la economía colonial, que muestra, desde mediados del siglo XVIII, los signos crecientes de una expansión ganadera sistemática producto de su orientación definitiva hacia el Atlántico, con su atención puesta en el comercio exterior.

En el presente trabajo se pondrá el acento en la evolución de los precios de la carne vacuna en el período colonial en la ciudad de Buenos Aires, que le imprimen una característica particular a este mercado local, como es su regularidad. Y también se intentará determinar los principales condicionantes que posibilitan esta regularidad, así como la ausencia, en este mercado en particular, de crisis estructurales.

Los fundamentos de nuestro estudio estarán puestos en la historiografía referida al tema y en las fuentes éditas sustentadas en las Actas del Extinguido Cabildo.'

De esta manera, se confrontarán los estudios históricos sobre el tema con las fuentes que muestran, desde diferentes aspectos, la relación del funcionamiento de la economía rioplatense colonial con el mercado de abasto de carne citadino.

\section{La carne vacuna en el ámbito del Río de la Plata}

La alimentación humana no es sólo un hecho económico sino también un hecho social ligado a una serie de simbolismos, representaciones y rituales.

En Hispanoamérica, en términos generales, el hábito de comer carne era una costumbre traída desde España que arraiga y se hace característica de la cultura y las costumbres de la sociedad española y criolla. Así, por ejemplo, Castillero-Calvo nos dice que para el panameño del siglo XVIII la carne vacuna era su base de alimentación. Torres Sánchez, por su parte, plantea que en Venezuela también el consumo de carne vacuna es fundamental, y su demanda se incrementa a mediados del siglo XVIII. Enriqueta Quiroz estudia y destaca la demanda de carne de res y carnero como uno de los ejes de la dieta de la ciudad de México, junto con el maíz. Enrique Tandeter-Wachtel, asimismo, refleja en sus estudios sobre el Alto Perú la importancia de la ingesta de carne vacuna en esta región. También Daniel Salazar destaca la carne vacuna como un alimento que forma parte de la dieta cotidiana del conjunto de la población.

En el ámbito del Río de la Plata el consumo de carne vacuna es fundamental. En este sentido, desde los tiempos de la Conquista, formaba parte de la dieta básica de sus pobladores, junto con los cereales y otras variedades de alimentos, y esto va estructurando un orden productivo que configurará costumbres, rituales y, desde la perspectiva económica, formas de subsistencia, producción y circulación que, junto con otros alimentos, constituirán los ejes fundamentales en el desarrollo de la economía rioplatense.

1 Actas del Extinguido Cabildo, sección: Abastos, 1773-1803. 


\section{Los precios de la carne vacuna de la ciudad de Buenos Aires colonial. Historia e historiografía}

La historia de los precios referida a América Latina colonial no gozó hasta mediados del siglo XX de un sistemático interés historiográfico. Y, de manera específica, para el caso del Río de la Plata, los avances no han sido sustanciales. Aun cuando la historia económica rioplatense se presenta en la actualidad con un panorama mucho más claro que el que existía en la segunda mitad del siglo XX, con progresos que han sido relevantes. Ciertamente, después del punto de inflexión trazado por Assadourian en los años sesenta de dicho siglo, respecto a la relevancia de los mercados locales y regionales, se dio en las dos últimas décadas, y hasta nuestros días, una renovación historiográfica que permitió conocer con mayor claridad mercados, circuitos de comercio interregional, así como los actores sociales involucrados, para mencionar algunos avances. $^{2}$

Sin embargo, en este contexto, "Entre las deficiencias actualmente existentes en el panorama de la historia económica rioplatense, una de las más acuciantes gira en torno a la falta de series completas y confiables de precios de bienes y factores. El período anterior a 1900 es, en Argentina, especialmente crítico [...]" (Djenderedjian y Martirén, 201, p. 38).

Es así que aún hoy, con todos los progresos que se han producido, parafraseando a Jorge Gelman todavía: "En grandes parcelas de la historia económica carecemos de las series de precios, salarios, producción, comercio interno y externo, población, familias, monedas, finanzas [...]" (Gelman, J, 2006, p. 10).

Refiriéndonos al mercado de carne vacuna en la ciudad de Buenos Aires colonial, las fuentes aparecen bastante áridas como para llegar a elaborar una serie de precios que posibiliten una visión clara o más profunda de lo que se ha venido trabajando hasta el momento. Por su parte, las investigaciones sobre el tema han sido poco profusas, en el marco de la historiografía vernácula.

En este sentido, respecto específicamente a los precios de productos básicos de consumo en el ámbito latinoamericano, uno de los trabajos pioneros ha sido el de Ruggiero Romano (1966 y 1983), quien, en su estudio sobre la región sur de Hispanoamérica colonial, plantea que los precios de los bienes que la población consumía cotidianamente en las ciudades de Chile y Buenos Aires muestran un estancamiento a lo largo del siglo XVIII, que no es más que una continuación de la estabilidad de precios que venía produciéndose desde la centuria anterior. Refiriéndose a todo el período colonial, y en el marco de la historia económica de América Latina, Ruggiero Romano muestra que los precios de los productos básicos de subsistencia, dentro de los cuales se encuentra la carne vacuna, para el poblador de la ciudad de Buenos Aires y Chile, permanecieron estables, en términos generales, "[...] con una ligera recuperación a fines del siglo XVIII, pero una recuperación que no permite de ninguna manera que los precios retomen el nivel de fines del siglo XVII y comienzos del XVIII" (1992, p. 150).

2 Respecto al tema, Jorge Gelman señala que la historia rural rioplatense: "[...] conoció un cambio radical para el período que abarca mediados del siglo XVIII y XIX, tanto por la gran cantidad de evidencia nueva aportada, como por las interpretaciones innovadoras que han transformado nuestra forma de pensar esta temática" (Gelman, 2006, p. 11). 
Este historiador tiene una mirada comparativa entre la economía de la Europa preindustrial y las sociedades coloniales hispanoamericanas, centrándose en las esferas de la producción y comercialización. Pone el acento particularmente en la coexistencia sistemática para las sociedades hispanoamericanas coloniales de una economía natural y una monetaria, así como en el hecho de que gran parte de la producción no pasaba por el mercado. Y, específicamente para el ámbito de las coloniales meridionales, la diversidad tanto en la producción como en el consumo de alimentos ilustra el carácter más resistente a las crisis de subsistencia, que posibilitaba un crecimiento poblacional sistemático.

En este ámbito, entonces, el movimiento de precios en las economías coloniales de Chile y el Río de la Plata se presenta relativamente estable, con una tendencia a largo plazo descendente, que estarían mostrando, a criterio de Ruggiero Romano, comportamientos opuestos entre la economía europea y la americana.

Johnatan Brown, por su parte, señala para la ciudad de Buenos Aires un crecimiento económico constante impulsado ya desde el siglo XVIII por la demanda del comercio exterior, que trae como consecuencia un importante incremento de la población, un dinamismo en la demanda de productos básicos de subsistencia y una suba de salarios que contrasta con la tendencia bajista de los precios en el mercado de Buenos Aires (Brown, 2002).

El investigador Lyman Johnson realiza en la década de 1990 una historia de precios y salarios durante el período virreinal, en la cual presenta para ambos una serie en forma correlacionada que permite tener una visión general de la economía local. Precisamente, su análisis fue producto de una interesante polémica historiográfica con Ruggiero Romano (cf. Ruggiero y Johnson, 1990). Cabe destacar, asimismo, que Lyman Johnson no se refiere en forma directa al precio de la carne vacuna, sino que deduce su costo a partir de la carne salada, uno de los componentes básicos de la dieta de los sectores populares de entonces.

Johnson llega a la conclusión que los salarios y precios de los productos de consumo básico del poblador de Buenos Aires ascienden desde 1776 hasta1781, cuando aparece una meseta, para incrementarse de nuevo entre 1802 y1807. De todas maneras, destaca que estos aumentos, y sobre todo el de la carne para el consumo, no modifican la economía básica, puesto que se dan — como señalamos — en forma conjunta con el aumento de salarios. Así también lo manifiesta Cuesta: "[...] no se conoce prácticamente nada acerca del impacto de estos [...] cambios económicos sobre el nivel de vida de la clase obrera colonial" (Cuesta, 2007, p.10).

En síntesis, Johnson plantea un alza de precios, precisamente, por su análisis en un período acotado, en el último cuarto del siglo XVIII, de modo que confirma en cierta manera los análisis que, dentro de la perspectiva de largo plazo, reconocen esta alza coyuntural.

El historiador Juan Carlos Garavaglia, en su investigación sobre la historia agraria de la campaña de Buenos Aires, refiriéndose al período que abarca desde mediados del siglo XVIII hasta 1826, viene a coincidir con Ruggiero Romano respecto al detenimiento de precios en el siglo XVIII, reconociendo también solo un alza coyuntural en los últimos años de dicha centuria. Sus mediciones están basadas en un primer estudio en los precios de inventario de las vacas de cría, y luego confirmados por los costos de la res (en pie) que ingresaba a los 
corrales oficiales. ${ }^{3}$ En el contexto general de la tendencia descendente de precios, destaca un alza coyuntural entre 1770 y 1774, un nuevo descenso y otro aumento entre 1785 y 1791, año a partir del cual se asiste, ahora sí hasta la década independiente, a un gradual descenso de los precios de la carne para consumo (Garavaglia, 1999). “Durante el período analizado se dibujan varios movimientos en los precios pecuarios. Partimos de la meseta inmediatamente alta en relación con el resto del período que sufre un violento descenso en los años 1763-1767 [...] para asistir después a un brusco movimiento de ascenso que termina también en forma repentina [...] cayendo nuevamente en 1774 al nivel más bajo de todo el período. Se inicia allí un nuevo movimiento ascendente que, con sacudidas leves, se extiende hasta 1785-1791. De 1791 a 1807 la situación es de una lenta pero ininterrumpida caída de los precios" (Garavaglia, 1995, p. 69).

De esta forma, en términos generales, Juan Carlos Garavaglia estaría confirmando la tesis de Ruggiero Romano, respecto a un estancamiento en el largo plazo de precios de productos pecuarios, con una leve alza a fines del siglo XVIII, para volver a la meseta hasta la primera década independiente.

Tomando otro estudio sobre el tema, desde la perspectiva arqueológica, Mario Silveira llega a conclusiones similares. Sustentado en una investigación sobre los restos de la comida proteica en la ciudad de Buenos Aires durante el amplio período que se extiende desde la fundación de Buenos Aires por Garay en 1580 hasta unos años después de mediados del siglo XIX, coincide en afirmar la estabilidad general de los precios de la carne para consumo, que perdura a lo largo del período colonial y hasta la etapa tardo-colonial. Fenómeno que era posible porque "[...] los estancieros sólo tenían dos posibilidades comerciales con el vacuno, el cuero y sebo, o la venta de la carne para el consumo en la ciudad. Justamente cuando se produce el auge del saladero a principios del siglo XIX, se da otra posibilidad comercial que generó problemas con el abasto de la ciudad" (Silveira, 2003, p. 10).

Silveira hace un análisis pormenorizado de los siglos XVII, XVIII y XIX sobre la comercialización y el precio de la carne. Realiza una relación directa entre el precio de los productos básicos de consumo y los salarios. Confecciona una serie de precios para todos estos siglos, en función del costo en reales por $\mathrm{kg} .{ }^{4}$ A partir de esta serie, encuentra ya en el siglo XVII precios "bajos y estables".

Este autor fundamenta, asimismo, una media en el precio de la carne vacuna de 0,069 reales por kg vivo para todo el siglo XVII, que al confrontarla con el nivel medio de salarios, estaría representando un promedio del $2 \%$ del salario diario de los empleados públicos que menos ganaban, como es el de un alguacil, ministro de Justicia, mesero del Cabildo o un soldado común del Fuerte. De esta manera, la carne vacuna se presenta como un producto asequible a todos los sectores sociales (incluidos los que recibían los menores salarios).

3 Por un lado, considera que las vacas de cría están relacionadas en forma directa tanto con el consumo interno como con el mercado mundial, a través de la exportación de cueros y carne salada (Garavaglia, 1995). Por otro lado, realiza un cálculo para las reses vivas que entraron al matadero entre 1788 y 1792 de 8 reales per cápita, que aumenta en 1792 a 12,2 reales (Garavaglia, 1999).

4 Respecto a la elaboración de su tabla de precios de carne para el consumo, Silveira afirma: "[...] Dado que por lo general la venta se efectuaba por cortes grandes, un cuarto del animal era lo común, hemos considerado que el peso de un animal gordo de consumo estaría en los 450 kilos, que el rinde de matanza era del $50 \%$ (el actual es del 57\%), con lo que obtenemos 225 kilos 'en el gancho'. Considerar en 40 kilos un cuarto, como hemos hecho, es un dato que pudo ajustarse bastante bien a la realidad" (Mario Silveira, 2003; p. 13). 
Para el siglo XVIII, por su parte, también muestra el bajo costo de los precios de la carne vacuna para consumo, así como una relativa estabilidad, aun cuando - y en esto hay una plena coincidencia con el resto de los autores que trabajan el tema- se produce una suba en la década de los ochenta, para volver a descender en la siguiente década. Respecto a la media, en este caso, estaría indicando una suba de $50 \%$ respecto al siglo anterior, puesto que ahora representa 0,112 reales por kg. Respecto a la proporción del costo de la carne vacuna con los salarios en este siglo, Silveira nos habla de un 2 a un 3\% de un empleado de Cabildo, uno de los sectores que menos salario recibía, índice similar al del siglo anterior.

Afirma Silveira (2003, pp. 16-17) : “Como se observa el valor de la carne se mantiene barato en el costo de la comida y muy por debajo del resto de los demás artículos, pese al aumento observado en la carne, que también se traslada al resto de los demás artículos de consumo [...]".

Estabilidad en los precios de la carne para consumo y carencia de crisis parecen ser la característica esencial.

Martín Cuesta, por su parte, coincide también respecto a la particularidad de estabilidad que poseen los precios de la carne vacuna para el consumo durante el período colonial. Teniendo como interés de análisis el crecimiento económico de Buenos Aires durante el siglo XVIII, confecciona una serie de precios de "larga duración" de los productos de consumo local, entre los que se encuentra la carne vacuna. A diferencia de Garavaglia y Silveira, Martín Cuesta elabora la serie en función del kg por res faenada, y también lo hace en reales.

Por su parte, Cuesta manifiesta que, en términos generales, los precios de los productos locales se mantuvieron estables a lo largo del siglo XVIII, pero "con una tendencia al alza durante todo el siglo [...]" (Cuesta, 2007, p. 18).

En este sentido, este historiador a diferencia de Romano o Garavaglia no habla de "estancamiento" secular, sino que pone el acento en esa "tendencia" al incremento de precios como un fenómeno característico del XVIII, destacando el período tardo-colonial, último cuarto del siglo, cuando se le atribuye este ascenso de precios a un incremento de la demanda provocado por el significativo aumento de la población, en consonancia con el crecimiento de la economía, que, en términos generales, es de un $2 \%$ anual a lo largo del siglo XVIII. En este sentido, Cuesta parece coincidir con Lyman Johnson.

Cabe aclarar, asimismo, que ninguno de los autores mencionados realiza una discriminación de los cortes. Uno de los motivos, creemos, es que, precisamente, la venta por cortes (tales como aguja, cuarto trasero, pecho, etcétera) es un fenómeno que aparecerá registrado en las fuentes recién a fines del siglo XVIII.

La estabilidad en los precios de la carne vacuna para consumo en Buenos Aires colonial, al igual que en otras ciudades hispanoamericanas como México o Santiago de Chile, aparece en el ámbito historiográfico como un hecho demostrado por la historiografía referida al tema. 
Cabe preguntarnos, entonces, cuáles son los principales condicionantes que inciden en esta característica sustancial.

\section{Algunos condicionantes de la regularidad de los precios de la carne para consumo en el contexto colonial}

Esta regularidad, demostrada por los investigadores precedentes, en los precios de la carne vacuna para el consumo estaría respondiendo, en el ámbito de Buenos Aires colonial, a varios factores.

En primer lugar, debemos tomar en cuenta dos elementos básicos. Por un lado, la fuerte regulación institucional que, a través del Cabildo, se ejercía sobre los productos esenciales de consumo, y por otro, su abundancia.

En este sentido, debe pensarse en un mercado inserto en el marco de una economía que aún no está reglada por el libre juego de la oferta y la demanda, un mercado incorporado a una sociedad todavía fuertemente caracterizada por los rasgos del Antiguo Régimen, donde predominan "[...] modelos que suponen asignaciones coactivas de factores, monopolios y rentas de asignación omnipresentes, costos de transporte restrictivos, así como transacciones realizadas en el interior de tramas de obligación personal [...]" (Moutoukias,2001 p. 7).

Los mecanismos institucionales de mediación para el abasto a las ciudades hispanoamericanas aparecían como una herencia del sistema de abastecimiento urbano del Antiguo Régimen castellano. En la península Ibérica, "La subsistencia era un concepto más rico que abarcaba las condiciones básicas de alimento y combustible necesario para la vida. Por ello los municipios disponían de un control muy estrecho sobre productos como el aceite, pescado, tocino o carne de vacuno o carnero [...]" (Luján Muñoz y Cabezas Carcache,1994, p. 664).

Precisamente, nos enfrentamos ante un mercado regulado de modo sistemático por el Cabildo, el cual pone un cuidado muy atento respecto al mantenimiento de la estabilidad en los precios de alimentos básicos para el consumo, para evitar, entre otras cosas, los conflictos que toda escasez implica. Ciertamente, el Ayuntamiento llevaba a cabo, en el ámbito de las ciudades hispanoamericanas coloniales, un estricto control sobre los precios de los alimentos básicos para la subsistencia, como es el caso, en este ámbito, de la carne vacuna, presionando para que se mantuvieran estables y accesibles, fundamentalmente para evitar problemas con los sectores populares.

Este control se intenta reforzar con las Reformas Borbónicas, puesto que estas se sustentan en la necesidad de ejercer un estricto dominio sobre la vida social de los pobladores de sus colonias. "El imperio de 'precios justos' era un componente esencial de la legitimidad social delos cabildos y no por nada uno de los cargos más prestigiosos era el de Fiel Ejecutor, es decir aquel que estaba encargado de asegurar y controlar los precios, los pesos y las medidas" (Garavaglia, 1999, p. 273).

Asimismo, la carne para consumo era un producto abundante y de fácil acceso para toda la población, otro condicionante que posibilita cierta regularidad en los costos: 
[...] La carne está en tanta abundancia que se lleva a cuartos a carretadas en la plaza, y si por accidente se resbala, como he visto yo, un cuarto entero, no se baja el carretero a recogerle, aunque se lo advierte y aunque por casualidad pase un mendigo, no le lleva a su casa porque no le cueste el trabajo de cargarlo [...]En los pagos y estancias no faltan todo género de carnes [...]. (Concolorcorvo, 1997, p. 255)

[...] un animal entero o media res, un costillar o una pierna. Lo que podía comerse se aprovechaba, si algo sobraba, lo devoraban los animales domésticos o se tiraba a la calle. (Azcarate, 1867, 15)

\section{[...] muchos pobres se mantienen con los desperdicios de las reses. ${ }^{5}$}

Debe tenerse en cuenta, por otra parte, que estamos ante un tipo de economía caracterizada por sus fuertes modalidades precapitalistas, es decir, una economía donde coexisten formas de circulación monetaria con una economía natural, como aparece en ciertas transacciones o en el pago de salarios rurales, formas de crédito, etcétera. De modo que, en un sistema que no se encuentra plenamente mercantilizado, y donde priman la abundancia del producto y los bajos costos, la estabilidad en sus precios es una consecuencia directa.

Ciertamente, el control institucional, sumado a la abundancia, tiene un efecto directo sobre el bajo costo de la carne vacuna.

En este sentido, los viajeros, por ejemplo, aun teniendo en cuenta su mirada etnocéntrica, informan sobre los bajos precios de la carne. Así, refiriéndose al poblador citadino porteño, Biscay de Azcarate (1867, p. 19) escribe: "Viven muy cómodamente y, a excepción del vino, que es algo caro, tienen toda clase de vituallas, como ser carne de vaca y ternera, de carnero y venado [...] y tan baratas que se puede comprar perdices a un penique la pieza y todo en proporción" (El subrayado es nuestro).

Y Silveira afirma al respecto: "La carne era realmente barata respecto a los demás artículos de consumo como a los sueldos que percibían. Lo único que se equipara en Buenos Aires en bajo costo era el pescado frito, insumo que era considerado también barato en la época colonial [...] En suma, la carne vacuna era accesible en todas las mesas por precio y disponibilidad todo el año [...]" (Silveira, 2003 p. 15).

Otro condicionante de la regularidad en los precios es el fenómeno de la expansión ganadera que comienza observarse en el Río de la Plata ya desde mediados del siglo XVIII. Desde la etapa borbónica, el ámbito hispanoamericano, y en especial sus ciudades portuarias, comienzan a relacionarse cada vez con mayor fuerza con el mercado mundial y sus demandas de materias primas, paralelamente con el debilitamiento constante de los vínculos con el Imperio español. En este contexto, el ámbito rioplatense, que funciona ya con total claridad en el siglo XVIII como importador de manufacturas y exportador de metálico, acentúa progresivamente su posición de exportador de productos pecuarios (cf. Schmit y Rosal, 1998 y 1999). En este sentido, la expansión ganadera, cuyo punto de inflexión será 1810 (Halperin Donghi, 1969 [1963]), impulsa el crecimiento de la producción de ganado porteño, lo que

5 Actas del Extinguido Cabildo (1771), sección: Abastos. 
incidirá positivamente en el incremento de carne para consumo. Este es uno de los factores que quizá, no obstante el sustancial crecimiento demográfico que se produce en la ciudad de Buenos Aires, sea otro de los condicionantes que influye en la regularidad de sus costos (con la sola excepción hecha entre 1770-1790, cuando, como se señaló, se produce una suba en la curva de los precios).

También, el comportamiento económico de los actores sociales involucrados en el circuito de producción-comercialización del mercado de carne local aparece mostrando su escaso poder de determinación sobre los precios.

De esta manera, quienes tienen en sus manos los circuitos de producción-comercialización del mercado local de carne vacuna son los pequeños y medianos productores de la campaña, luego, los intermediarios - comerciantes, que llevan el ganado vacuno a pie desde la campaña hasta los corrales de la ciudad de Buenos Aires - los invernan y los venden al Fiel Ejecutor (empleado del Cabildo que recibe las reses y las destina para su matanza), y por último los carniceros, que proveen las reses faenadas directamente para el consumo.

En este circuito, los productores de vacunos para el mercado local son predominantemente muy pequeños y pequeños, mostrando un importante grado de diversificación. Algo similar sucede en el contexto de la comercialización, donde, si bien los abastecedores o reseros se identifican claramente como un grupo dedicado a este tipo de mercado, sus transacciones son de manera predominante pequeñas ${ }^{6}$. Estos últimos se diferencian sustancialmente de los comerciantes conectados con el mercado transatlántico. Su característica esencial es su actuación como gremio (en términos de Antiguo Régimen). Asimismo, viven en barrios en los alrededores de los mataderos en condiciones muy básicas de subsistencia, formando parte del sector de "pequeños comerciantes". Sus quejas — respecto a los perjuicios que los llevan a que sus costos de ganancia sean bajos, por otra parte- son constantes, y en ellas puede deducirse su grado de alteridad respecto a los comerciantes que tienen como destino otros mercados, fundamentalmente los que miran al exterior. En este sentido, puede observarse el control estricto que el Cabildo ejerce sobre ellos impidiendo que aumenten los precios de las reses para consumo y exigiéndoles el cumplimiento del pago de impuesto por res viva ingresada (dos reales per cápita).

De este modo, como ya se señaló, el Cabildo aparece en este contexto ejerciendo todavía una voluntad paternalista, instituida por la Corona desde sus inicios, que forma parte de un repertorio institucional de una cultura jurídica que todavía prevalece, donde pareciera que las normativas del libre mercado resultan, aún, difíciles de imponer.

A este hecho se le suma la existencia de un mercado paralelo, que en las fuentes aparece como una amenaza constante para quienes se dedican "formalmente" a este comercio, con los costos y limitaciones que implica para la comercialización de carne para consumo.

Las quejas de reseros o abastecedores, por la venta ilegal de carne para el abasto público, son continuas en el ámbito del órgano formal de representación, como es el Cabildo:

6 El promedio mensual de ganado vacuno, per cápita, que los productores envían al corral para el abasto es de 25,3 vacunos, mientras que el de los abastecedores es de19,9 (Dupuy, A: 2013, p. 10). 
Igualmente previene a V.S. que se halla impuesto de que varios sujetos se han dedicado a matar reses en las inmediaciones de esta ciudad, distante de los corrales, por no pagar derecho alguno y traen la carne a vender al pueblo [...].7

Se hizo presente por los señores Alcaldes, que en atención al desorden que se ha notado según noticias que se les ha dado en la Matanza de los ganados, así para el abasto de esta ciudad, como en los extramuros y chacras, en que se incluyen muchas vacas y terneraje con grave perjuicio del fomento de la especie tan necesario así para el abasto, como para el fomento, y conservación del Importante ramo de comercio de cueros; [...] en las campañas no existen ya Ganados grandes, lo que necesita de pronto remedio para evitar el caso ruinoso de su falta para el preciso abasto de esta capital y su Jurisdicción [...]. ${ }^{8}$

De esta forma, si unimos precios controlados por el Ayuntamiento al comercio clandestino-que aun cuando no se puede medir la envergadura del mismo, minimiza la efectividad del mercado formal-, llegamos a una visión más clara de ese comportamiento constante en los precios.

Así, este poco margen de ganancia por parte de los sectores sociales que tienen en sus manos este mercado local, precisamente por su carácter sustancial de grupo diversificado, determina que no constituyan un elemento de presión suficiente que pudiera incidir en el incremento de los costos de la carne para el consumo. Este escaso poder de presión, entonces, constituiría otro condicionante de la estabilidad e inelasticidad de los precios. ${ }^{9}$

[...] y particularmente siempre que se note descuido de parte de los Reseros o Matanzeros en cumplir con las preinsertas calidades en los que les toca, o abuso en no tener provistos con abundancia los puestos destinados para el abasto de carne, o de aumentar el precio de ellas con pretexto de lluvias o tiempos menos favorables para el acopio de ganados, pues permitiendo que continúen este abasto, debe ser uno de sus principales cuidados tener preparados algunos repuestos en proporcionadas distancias. $^{10}$

Por último, tampoco los carniceros constituyen un factor de incidencia respecto a los precios de los productos de consumo básico local. Este grupo aparece como el más débil y desdibujado en las fuentes.

Esta situación de relativa estabilidad en los precios permanecerá regular hasta los primeros años de la etapa independiente, en el contexto de una economía ya fuertemente mercantilizada en el ámbito del libre juego de la oferta y la demanda, cuando aparecen otros factores en juego que inciden sustancialmente en el incremento de los precios.

7 Actas del Extinguido Cabildo (1802), sección: Abastos.

8 Actas del Extinguido Cabildo (1972), sección: Abastos.

9 Cabe aclarar que estos pequeños y muy pequeños realizan otras actividades, además de la venta de reses para consumo.

10 Actas del Extinguido Cabildo (1803), sección: Abastos. 


\section{Algunas consideraciones respecto al aumento de precios a fines del siglo XVIII}

No obstante la tendencia regular de precios en el mercado local de carne vacuna, debe considerarse una situación coyuntural, que se produce en el último cuarto del siglo XVIII, cuando aumentan, si bien en forma poco significativa, los precios de la carne para el consumo. Los autores mencionados que destacan este fenómeno no ahondan sobre sus causas. Solo puede subrayarse la sequía muy importante que se produce en 1772, que pudo ser el principal motivo del incremento de precios que se produjo entre 1771 y 1774.

Y luego, el aumento que tuvo lugar entre 1785 y 1791, que parece ser el resultado combinado de la gran sequía de 1777, sumado a la disminución de las exportaciones de cuero, y, por último, la peste ("el mal de rastrojo") que invade la campaña por esos años (Cuesta, 2009). Así como el crecimiento demográfico destacable que se produce durante la segunda mitad del siglo XVIII. Factor considerado como sustancial por Cuesta en el incremento de precios.

Aun así, puede plantearse, respecto a la carne vacuna para el consumo, una estabilidad de precios en el transcurso de la etapa colonial, con períodos cortos de aumentos que matizan esta situación general.

\section{El mercado local en el ámbito de la economía ganadera en su conjunto}

La regularidad marcada, la falta de crisis coyunturales importantes y la estabilidad característica que presenta en el transcurso del período colonial el mercado de carne vacuna en la ciudad de Buenos Aires dan muestras de una incidencia estable y constante de este mercado en la economía ganadera en su conjunto. En este sentido, se observa un sector social de productores y abastecedores, así como comerciantes minoristas que plantean su actividad de subsistencia en función de la venta (aunque estacional, atomizada) de los ganados que produce la campaña rioplatense.

Luego, en el contexto de una economía en expansión, ya desde mediados del siglo XVIII, la producción de ganado para consumo acompaña este crecimiento, así como va respondiendo al incremento demográfico que se manifiesta en Buenos Aires.

De esta forma, el mercado de abasto de carne para consumo constituirá un eslabón fundamental entre las piezas que conforman la economía colonial rioplatense, con sus sesgos marcadamente orientados a la producción agropecuaria, dentro de la cual la ganadería constituye una pieza fundamental.

La regularidad que presentan sus precios a lo largo del período indica los mecanismos institucionales que actúan sobre este mercado, así como otros factores que lo movilizan. Y, ya en la etapa tardo-colonial, cuando el mercado externo comience a incidir cada vez con más fuerza en la producción ganadera, los precios, con sus aumentos coyunturales-aun cuando sin mayor incidencia en la economía en su conjunto-, darán muestras de signos de cambios y de relaciones de fuerza entre mercado local y mercado externo, así como de la acentuación 
de formas de comercialización que van señalando la inclinación a una economía fuertemente mercantilizada, en el ámbito de una estructura capitalista que va imponiéndose poco a poco.

\section{A modo de conclusión}

“¿Qué objeto tiene estudiar los precios en un ambiente casi carente de circulación monetaria, donde los salarios son generalmente nominales, donde en definitiva la mayoría de la población no compra nada?" (De Ramón y Larrain, 1982, p.102).

La respuesta a este interrogante nos remite a reflexionar sobre la importancia de los mercados en el marco de las economías de Antiguo Régimen que movilizaban e interrelacionaban espacios geográficos y culturales diversos. Los precios nos vinculan de un modo directo con la producción y la demanda de bienes fundamentales en la conformación de la economía de los espacios hispanoamericanos.

Precisamente, en el presente trabajo se han tomado como eje de análisis los precios de la carne vacuna para el consumo en la ciudad de Buenos Aires colonial, porque creemos que constituyen un elemento clave para poder ampliar nuestra comprensión respecto al funcionamiento de este mercado local y la economía en su conjunto.

Pensando en términos de una economía mercantilizada pero que todavía se debate entre dos mundos sociales, el uno declinante, paternalista, reglado por la costumbre, con una lógica de relaciones sociales jerárquicas, con — todavía - formas de negociación precapitalistas, y el otro, naciente, fuertemente mercantilizado, con nuevos circuitos que imponen otras dinámicas de intercambio; monetizado, que intenta imponer nuevas conductas y una nueva normativa de mercado.

En el contexto de nuestro análisis, el Cabildo ejerce un estricto control sobre los precios de los productos básicos de subsistencia. Este control es uno de los factores fundamentales que impiden movimientos bruscos, así como aumentos prolongados de precios de la carne para consumo. Por su parte, esto es posible porque la disponibilidad de ganado vacuno de la campaña hace que, aun en períodos de escasez por diferentes causas, como sequías, excesivas lluvias o pestes, no se lleguen a producir crisis profundas que pudieran disparar los precios en forma intensa.

Por su parte, quienes detentan los circuitos de producción-comercialización constituyen, de manera predominante, un sector de pequeños y muy pequeños productores y comercializadores que se muestra diversificado y ejerciendo transacciones pequeñas, que no pueden llegar a incidir para que esta regulación institucional tan marcada se modifique o dé lugar al libre juego de la oferta y la demanda, lo que pudiera trasuntar cambios importantes en los precios de carne para el consumo.

Aun así, hubo coyunturas puntuales, tales como las de principios o último cuarto del siglo XVIII, en las que puede observarse una suba de precios. Suba que, no obstante, no llega a manifestarse como significativa en el marco de una economía en expansión. 
Así pues, puede concluirse, en consonancia con la historiografía referida al tema, que el mercado local de carne vacuna de la ciudad de Buenos Aires colonial fue, en términos generales, simple, lineal, con una regularidad que lo define. Un mercado local que viene a acompañar, en un marco de relativa estabilidad, a los movimientos de una economía en expansión que va poniendo sus fuerzas en las posibilidades que va ofreciendo el mercado externo, mercado este último que no sería posible sin un mercado local estable que lo sustente.

\section{Referencias}

Azcaráte, D. B. (1867). Relación de los viajes de Monsieur Azcaráte Du Biscay al Río de la Plata, y desde aquí hasta el Perú, con observaciones sobre estos países. Trad. del inglés por Daniel Maxwell. En Revista de Buenos Aires. Tomo XIII. Año V, № 49.

Brown, J. (2002 [1979]). Historia socio-económica de la Argentina, 1776-1860. Buenos Aires: Instituto Di Tella - Siglo Veintiuno Editores.

Concolorcorvo. (1997). Lazarillo de ciegos caminantes. Buenos Aires: Emecé Editores.

Cuesta, M. (2009). Precios, población, impuestos y producción. La economía de Buenos Aires en el siglo XVIII. Buenos Aires: Temas Grupo Editorial.

Cuesta, M. (2007), Precios y mercados en Buenos Aires en el siglo XVIII. Am. Lat. Hist. Econ., vol. 14, núm. 2, julio-diciembre, pp. 25-57.

De Ramon, A y Larrain, J. M. (1982). Orígenes de la vida económica chilena. Santiago de Chile:Centro de Estudios Públicos.

Djenderedjian, J. y Martirén, J. L. (2013). Los precios de los bienes en las fronteras bravías del Río de la Plata colonial: Santa Fe durante la primera mitad del siglo XVIII. Am. Lat. Hist. Econ., 20 (2): 36-66.

Dupuy, A. (2013). Mercado de abasto de carne en Buenos Aires colonial (siglos XVI- XVIII). Cambios y continuidades. Madrid: Editorial Académica Española.

Dupuy, S, (2012). "Productores y abastecedores en el mercado de abasto de carne a la ciudad de Buenos Aires tardo-colonial". En: III Congreso Latinoamericano de Historia Económica y XXIII Jornadas de Historia Económica - Bariloche.

Garavaglia, J. C. (1995). Precios de los productos rurales y precios de la tierra en la campaña de Buenos Aires: 1750-1826. Boletín del Instituto de Historia Argentina y Americana "Dr. Emilio Ravignani". Tercera serie, núm. 1.

Garavaglia, J.C. (1999). Pastores y labradores de Buenos Aires. Una historia agraria de la campaña bonaerense, 1700-1830. Buenos Aires: Ed. La Flor.

Gelman, J. (comp.). (2006). La historia económica argentina en la encrucijada. Balances y perspectivas. Introducción. Buenos Aires: Prometeo.

Halperin Donghi, T. (1969 [1963]). La expansión ganadera en la campaña de Buenos Aires (1810-1852), pp.11-45. En T. Di Tellay T. Halperin Donghi, Buenos Aires: Los fragmentos del poder. Ed. Jorge Alvarez. 
Luján Muñoz, J. y Cabezas Carcache, H. (1994). Historia de Guatemala. Guatemala: Asociación Amigos del País - Fundación para la Cultura y el Desarrollo, pp. 653-663.

Moutoukias, Z. (2001), Peut-on faire l'economie d' une économie politique, en: Editions de I'EHESS | Annales. Histoire, Sciences Sociales 2001/6 - 56e année, pp. 1111 - 1128.

Moutoukias, Z. (2000). Gobierno y sociedad en el Tucumán y en el Río de la Plata, 1500-1800. En: Nueva Historia Argentina. La sociedad colonial. Tandeter (dir), Buenos Aires: Sudamericana, pp. 357-411.

Romano, R. (1963), "Movimiento de los precios y desarrollo económico: el caso de Sudamérica en el siglo XVIII", Desarrollo Económico, vol. 3, núm. 1-2, abril-septiembre, pp. 341-346.

Romano, R. (2004). Mecanismo y elemento del sistema económico colonial americano, siglos XVI-XVIII. México: Fondo de Cultura Económica/Fideicomiso, Historia de las Américas.

Romano, R. y Johnson, L. (1990). Notas y debates. Una polémica acerca de la historia de precios en el Buenos Aires virreinal. Boletín del Instituto de Historia Argentina y Americana "Dr. Emilio Ravignani". Tercera serie, $\mathrm{N}^{\circ} 2$.

Silveira, M. (1972). Cocina y comidas en el Río de la Plata. Neuquén: Universidad Nacional del Comahue.

Silveira, M. (2003). Historia para arqueólogos. La cadena alimenticia del vacuno: época colonial y siglo XIX y su relación con el uso del espacio en la ciudad de Buenos Aires. Buenos Aires: Instituto de Arte Americano en Investigaciones Estéticas.

Schmit, R. y Rosal, M. A.(1998). Las exportaciones del Litoral argentino al puerto de Buenos Aires entre 1783-1850. Revista de Historia Económica, Nº 3adrid: Alianza.

Schmit, R. y Rosal, M.A. (1999). Política comercial, flujos mercantiles y negocios: Buenos Aires y Montevideo frente al comercio exterior rioplatense en el siglo XIX. Madrid: CSIC.

\section{Fuentes éditas}

Actas del Extinguido Cabildo (1773,1777, 1801-1803), sección: Abastos. 